\title{
Virulence of the amphibian chytrid fungus Batrachochytrium dendrobatidis varies with the strain
}

\author{
Lee Berger ${ }^{1, *}$, Gerry Marantellii ${ }^{2}$, Lee F. Skerratt ${ }^{3}$, Rick Speare $^{1}$ \\ ${ }^{1}$ Amphibian Disease Ecology Group, School of Public Health, Tropical Medicine and Rehabilitation Sciences, \\ James Cook University, Townsville, Queensland 4811, Australia \\ ${ }^{2}$ Amphibian Research Centre, New Farm Road, Werribee, Victoria 3030, Australia \\ ${ }^{3}$ Amphibian Disease Ecology Group, School of Veterinary and Biomedical Sciences, James Cook University, \\ Townsville, Queensland 4811, Australia
}

\begin{abstract}
Although mortality in 3 groups of 15 green tree frogs Litoria caerulea exposed to 3 isolates of Batrachochytrium dendrobatidis was $100 \%$, time to death varied with isolate, highlighting the importance of strain and/or passage history in pathogenicity studies and possibly in the epidemiology of chytridiomycosis. A standard naming scheme for isolates of $B$. dendrobatidis is proposed.
\end{abstract}

KEY WORDS: Batrachochytrium dendrobatidis · Amphibian chytrid fungus · Chytridiomycosis · Amphibian · Strain variation · Virulence $\cdot$ Litoria caerulea

\section{INTRODUCTION}

Chytridiomycosis, caused by the amphibian chytrid fungus Batrachochytrium dendrobatidis, is an emerging infectious disease that has spread worldwide causing amphibian population declines and extinctions in several countries (Berger et al. 1998, 1999, Daszak et al. 1999, Carey et al. 2003). Epidemiological evidence suggests that $B$. dendrobatidis originated in Africa and escaped from that continent during the global trade in Xenopus laevis (Weldon et al. 2004). Mortality rate and time to death is affected by fungal dose, temperature, age of frogs, and host species (Berger et al. 1999, 2004, Ardipradja 2001, Lamirande \& Nichols 2002, Woodhams et al. 2003). However, the effects of strain and/or passage history of the fungus on pathogenicity and virulence have not been examined.

Minor physiological differences between isolates from Australia have been reported despite multilocus sequence typing which showed that isolates from different parts of the world including Australia are genetically similar (Johnson \& Speare 2003, Morehouse et al. 2003). It is important that the pathogenicity of isolates used in experiments is uniform, or if not uniform, at least characterized for individual isolates to enable comparison of susceptibility of different amphibian species, an assessment recommended as necessary for effective conservation management (Speare et al. 2001, Department of Environment and Heritage 2004).

Three isolates of Batrachochytrium dendrobatidis with different passage histories were used at the same dose rate to infect a cohort of juveniles of the green tree frog Litoria caerulea to determine if there was variation in the pathogenicity and virulence of the isolates.

\section{MATERIALS AND METHODS}

Frogs used in the experiments were captive-bred juveniles (17 to $26 \mathrm{~mm}$ snout-vent length) of Litoria caerulea from a single spawning group from the Amphibian Research Centre (ARC), Melbourne, Victoria, Australia, that had metamorphosed 3 to 6 wk earlier. They were housed individually in clear plastic $1.4 \mathrm{l}$ tubs (Hagen mini PalPens) with gravel at one end. Frogs were fed crickets twice a week. Automatic drippers flushed through 21 of tap water daily. Tubs were placed side-by-side on shelves separated by plastic sheeting. For each tub, separate equipment and a new pair of disposal latex gloves were used. This arrange- 
ment along with automated water flow was highly effective in preventing cross-contamination as evidenced by the lack of infection in the tubs of control frogs that were placed randomly among infected tubs. Room temperature varied between 16 and $20^{\circ} \mathrm{C}$.

Isolates of Batrachochytrium dendrobatidis were obtained from sick frogs by culturing on tryptone/ gelatin hydrolysate/lactose (TGhL) agar with antibiotics (Longcore et al. 1999). The 3 strains were (1) strain 98 1469/10 cultured from a captive-bred metamorph of Limnodynastes dumerilii from the ARC (17 mo old culture), (2) strain 99 1385/12 cultured from a wild adult of Litoria caerulea from Rockhampton, Queensland (9 mo old culture), and (3) strain 00545 cultured from a captive metamorph of Litoria lesueuri from the ARC that had been collected as a tadpole from Gibbo River, north-eastern Victoria (1.5 mo old culture). Cultures were maintained in TGhL broth at $4^{\circ} \mathrm{C}$ and were passaged every 2 to 3 mo.

Zoospores were collected from 4 d old agar cultures, prepared from actively growing 1 wk old broth cultures at $22^{\circ} \mathrm{C}$. Zoospores were harvested by flooding plates with distilled water for $5 \mathrm{~min}$, then removing water by pipette. The concentration of zoospores was counted in a counting chamber. The zoospore suspension was stored in plastic tissue culture flasks and kept below $20^{\circ} \mathrm{C}$ until frogs were infected within $6 \mathrm{~h}$. The motility of zoospores was confirmed by microscopic examination immediately before infections were conducted.

Litoria caerulea were exposed individually in the dark to 50000 zoospores in $5 \mathrm{ml}$ distilled water in $45 \mathrm{~mm} \times 50 \mathrm{~mm}$ yellow top specimen containers (Labserv) for $24 \mathrm{~h}$. Fifteen frogs were exposed to strains 98 1469/10 and 00545 and 14 to strain 99 $1385 / 12$. Fifteen control frogs were also treated this way, except that they were exposed to water washed off a clean agar plate.

Chytridiomycosis was diagnosed at Day 19 by histology of toe clips, and at death by examination of shedding epidermal sheets (Berger et al. 1999) from all frogs and by histology on 5 individuals per group. The experiment was terminated when the last infected frog died. Frogs were euthanized when clinical signs of disease became obvious by bathing in $0.2 \%$ MS 222 (tricaine methanesulfonate) (Ruth Consolidated Industries). Lethargy and a delayed righting reflex were considered to indicate that death was certain. As there is usually a short period of time $(<2$ d) from onset of obvious clinical signs until death, euthanasia is not likely to significantly affect a comparison of times until death among frogs. In the results, frogs are described as having 'died' whether they were euthanized or died naturally. Frogs were then fixed whole in $10 \%$ formalin. The experiment was performed under James Cook University Ethics Committee approval number A736_02.
The times until death were compared among infected groups for significant differences using nonparametric tests due to the skewed distribution. The Kruskal-Wallis test was used for comparison among all groups and the Mann-Whitney $U$ for comparison between 2 groups using SPSS version 12 (SPSS).

\section{RESULTS}

All frogs in the infected groups died whereas control frogs remained healthy. However, time until death was significantly different among infected groups $(\chi=30.5$, $\mathrm{df}=2, \mathrm{p}<0.001$ ). Frogs exposed to zoospores of strain 00545 died significantly sooner $(\mathrm{p}<0.001)$ than frogs exposed to the other 2 isolates (Fig. 1). Frogs exposed to zoospores from strain 98 1469/10 died significantly sooner $(p=0.03)$ than frogs exposed to 99 1385/12 (Fig. 1). The mean time till death of frogs infected with 00545 was $19.4 \pm 4.17 \mathrm{~d}$ (range 9 to $28 \mathrm{~d})(\mathrm{n}=15)$, with 99 1385/12 was $37.9 \pm 9.3$ d (range 30 to 67 d) $(n=14)$ and with 98 1469/10 was $32.7 \pm 6.8$ d (range 24 to $52 \mathrm{~d}$ ) $(\mathrm{n}=15)$. Chytridiomycosis was confirmed in all frogs in the 3 infected groups, apart from 3 exposed to 00545 that were not examined as they died without premonitory signs and were only found when autolyzed. However, exclusion of these individuals did not affect the results of the statistical analysis. Batrachochytrium dendrobatidis was not found in the control frogs.

Using histology of toe tips to monitor the progress of infection, chytridiomycosis was found at Day 19 in 8/8 $(100.0 \%)$ frogs exposed to strain 00 545, in $9 / 15$ $(60.0 \%)$ exposed to strain $981469 / 10$ and in 10/14 (71.4\%) exposed to strain 99 1385/12.

The first signs of disease were that frogs were more likely to be found on the floor of the enclosure rather than sitting high on the walls, and they appeared less active. Their skin became blotchy and

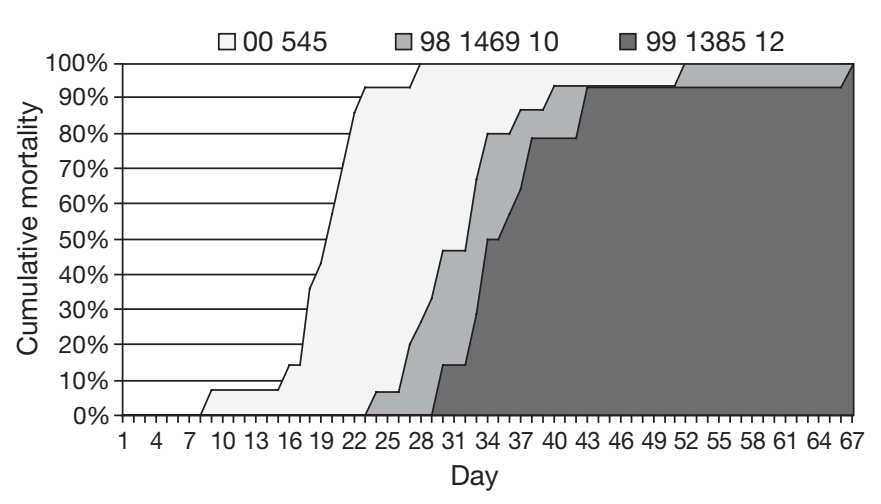

Fig. 1. Litoria caerulea. Cumulative mortality in green tree frogs over time post-exposure to 3 strains of Batrachochytrium dendrobatidis 
accumulations of shedding skin were visible over the body. They soon became inappetant, lethargic and sat in abnormal postures with hind legs abducted.

\section{DISCUSSION}

This experiment demonstrated that Batrachochytrium dendrobatidis is highly pathogenic to Litoria caerulea and $100 \%$ mortality occurred with all isolates, but the time till death differed with strain. $L$. caerulea is a highly susceptible host compared with 3 other species (Limnodynastes tasmaniensis, Mixophyes fasciolatus and Litoria chloris) (Ardipradja 2001) and perhaps there would have been differences in mortality rates if a more resistant species had been used.

The differences in virulence with strain could be associated with environmental and host selection pressures reflecting the different locations and host species for each isolate. The 3 strains were isolated from 3 locations (2 in Victoria and 1 in Queensland) and from 3 amphibian species, 2 from the hylid genus Litoria and 1 from the myobatrachid genus Limnodynastes. Alternatively, differences in in vitro management of the isolates could select for differences in virulence, as the time since isolation also varied between strains. Variation in the production of biochemical metabolites commonly occurs during laboratory cultivation of fungi (Turner 1971). Cultures were still pathogenic even after 17 mo of growth in vitro (approximately 12 passages). However, there were significant differences in the time to death. The most virulent strain was the most recently isolated (isolated 1.5 mo earlier). Although rate of passage of these strains was low owing to their being held at $4^{\circ} \mathrm{C}$, these results suggest that the possibility of attenuation of strains by passage in vitro should be studied. As a method to cryopreserve isolates of Batrachochytrium dendrobatidis has recently been developed (Boyle et al. 2003), it is now possible to solely examine effects of passage.

Accurate identification of strains using a system with global application is essential. Currently, there is no standard naming system for isolates of Batrachochytrium dendrobatidis. We propose a naming scheme that incorporates (1) locality of the isolation, (2) amphibian host, (3) year, (4) initials of collector and (5) number of isolate from that particular combination. For example, our strain 00545 isolated from a Litoria lesueuri from Gibbo River would be named 'Gibbo River-Llesueuri-00-LB-1' and our strain 98 1469/10 would be 'Melbourne-Ldumerilii-98-LB-1'. The history of a strain should also be recorded, particularly the passage number which could be added as an additional number; e.g. for the 22nd passage of strain 99 1385/12 from Litoria caerulea at Rockhampton the name would be 'Rockhampton-Lcaerulea-99-LB-1p22'. For cryopreserved strains, passage number could recommence from the last passage prior to freezing.

This experiment and previous work show that although there is little genetic variation between isolates of Batrachochytrium dendrobatidis worldwide (Morehouse et al. 2003), different strains exist with significantly different virulence and behavior. It remains to be determined what selection pressures affect virulence. Regardless, the possibility of differences in virulence highlights the importance of minimizing movement of $B$. dendrobatidis even in chytrid-positive regions and countries. Wildlife and disease management strategies that regulate and limit movement of amphibians within countries should be promoted and chytrid-positive countries, such as Australia, that do not require freedom from chytridiomycosis as a condition of importation (Biosecurity Australia 2003) should revise their regulations.

Acknowledgements. Thanks to R. Hobbs for help with animal care. This work was supported by the Australian Research Council, Environment Australia and the Department of Environment and Heritage.

\section{LITERATURE CITED}

Ardipradja K (2001) A study of resistance towards the emerging pathogen Batrachochytrium dendrobatidis in four species of Australian frogs. Honours thesis, University of Melbourne

Berger L, Speare R, Daszak P, Green DE and 10 others (1998) Chytridiomycosis causes amphibian mortality associated with population declines in the rain forests of Australia and Central America. Proc Natl Acad Sci USA 95: 9031-9036

Berger L, Speare R, Hyatt A (1999) Chytrid fungi and amphibian declines: overview, implications and future directions. In: Campbell A (ed) Declines and disappearances of Australian frogs. Environment Australia, Canberra, p 23-33

Berger L, Speare R, Hines H, Marantelli G and 10 others (2004) Effect of season and temperature on mortality in amphibians due to chytridiomycosis. Aust Vet J 82:31-36

Biosecurity Australia (2003) Quarantine requirements for the importation of amphibians or their eggs into zoological facilities. Animal Biosecurity Policy Memorandum, Canberra 2003/26

Boyle DG, Hyatt AD, Daszak P, Berger L, Longcore JE, Porter D, Hengstberger SG, Olsen V (2003) Cryo-archiving of Batrachochytrium dendrobatidis and other chytridiomycetes. Dis Aquat Org 56:59-64

Carey C, Bradford DF, Brunner JL, Collins JP and 5 others (2003) Biotic factors in amphibian population declines. In: Lindre G, Krest SK, Sparling DW (eds) Multiple stressors and declining amphibian populations. Society for Environmental Toxicology and Chemistry Press, Pensacola, FL, p 153-208

Daszak P, Berger L, Cunningham AA, Hyatt AD, Green DE, Speare R (1999) Emerging infectious diseases and amphibian population declines. Emerg Inf Dis 5:735-748 
Department of Environment and Heritage (2004) Threat Abatement Plan for infection of amphibians with chytrid fungus resulting in chytridiomycosis. Department of Environment and Heritage, Canberra

Johnson M, Speare R (2003) Survival of Batrachochytrium in water: quarantine and disease control implications. Emerg Infect Dis 9:922-925

Lamirande EW, Nichols DK (2002) Effects of host age on susceptibility to cutaneous chytridiomycosis in blue and yellow poison dart frogs (Dendrobates tinctorius). In: McKinnell RG, Carlson DL (eds) Proc 6th International Symposium on the Pathology of Reptiles and Amphibians. Saint Paul, MN, p 3-13

Longcore JE, Pessier AP, Nichols DK (1999) Batrachochytrium dendrobatidis gen. et sp. nov., a chytrid pathogenic to amphibians. Mycologia 91:219-227

Morehouse EA, James TY, Ganley ARD, Vilgaly R, Berger L, Murphy PJ, Longcore JE (2003) Multilocus sequence

Editorial responsibility: Peernel Zwart, Utrecht, The Netherlands typing suggests the chytrid pathogen of amphibians is a recently emerged clone. Mol Ecol 12:395-403

Speare R, Core Working Group of Getting the Jump on Amphibian Disease (2001) Developing management strategies to control amphibian diseases: decreasing the risks due to communicable diseases. Townsville, Australia: School of Public Health and Tropical Medicine, James Cook University, Townsville, Australia. Available from www.jcu.edu.au/school/phtm/PHTM/frogs/ampdis.htm

Turner WB (1971) Fungi, their cultivation and their secondary metabolism. In: Fungal metabolites. Academic Press, New York, p 11-25

Weldon C, du Preez LH, Hyatt AD, Muller R, Speare R (2004) Origin of the amphibian chytrid fungus. Emerg Infect Dis 10:2100-2105

Woodhams DC, Alford RA, Marantelli G (2003) Emerging disease cured by elevated body temperature. Dis Aquat Org 55:65-67

Submitted: March 29, 2005; Accepted: June 20, 2005

Proofs received from author(s): September 21, 2005 